\title{
Nanocomposite Hole-Extraction Layers for Organic Solar Cells
}

\author{
Jiao Li, ${ }^{1,2}$ Juncheng Liu, ${ }^{1}$ Congjie Gao, ${ }^{2}$ and Guohua Chen ${ }^{2}$ \\ ${ }^{1}$ School of Materials Science and Engineering, Shandong University of Technology, Zibo 255049, China \\ ${ }^{2}$ College of Chemistry and Chemical Engineering, Ocean University of China, Qingdao 266003, China
}

Correspondence should be addressed to Juncheng Liu, jchliu01@163.com

Received 15 August 2010; Accepted 9 November 2010

Academic Editor: Mohamed Sabry Abdel-Mottaleb

Copyright (C) 2011 Jiao Li et al. This is an open access article distributed under the Creative Commons Attribution License, which permits unrestricted use, distribution, and reproduction in any medium, provided the original work is properly cited.

\begin{abstract}
The influence of nanocomposite hole-extraction layers on the performance of organic photovoltaic (OPV) cells based on blends of poly(3-hexylthiophene) ( $\left.\mathrm{P}_{3} \mathrm{HT}\right)$ and [6,6]-phenyl-C-61-buytyric acid methyl ester (PCBM) has been investigated. The holeextraction layers consist of poly(3,4,-ethylene dioxythiophene) polystyrene sulfonic acid (PEDOT:PSS) doped with different concentrations of multiwall carbon nanotubes (MWCNTs). Compared with a pristine device (i.e., without MWCNTs), the MWCNTs-doped OPV cells shows an improved short-circuit current density, fill factor, and power conversion efficiency from 8.82 to $9.03 \mathrm{~mA} / \mathrm{cm}^{2}, 0.43$ to 0.474 , and $2.12 \%$ to $2.39 \%$ (i.e., by about $13 \%$ ), respectively. Reasons for the improved performance of the devices are discussed. It shows that the reduction of series resistance of the devices might be correlated with the improvement of the OPV cells, performance achieved through the incorporation of MWCNTs into the hole-extraction layer of PEDOT:PSS.
\end{abstract}

\section{Introduction}

Organic photovoltaic (OPV) cells have attracted much attention in recent years due to their advantages of low-cost manufacturing, light weight, and good flexibility [1-4]. OPV cells are thin film structures, in which organic photoactive materials are sandwiched between two electrodes. The ITO glass is generally employed as the anode in OPV cells because of its good electrical conductivity, high transparency over the visible region, and ease of patterning. However, the work function of ITO is quite low $(\sim 4.6 \mathrm{eV})$ [5]. As a result, great efforts have been made to modify the ITO anode, such as various treatments of the ITO surface $[6,7]$ and the deposition of very thin buffer layers between the ITO and the photoactive layer [8-10] in order to enhance OPV cells, performance. Thin films of PEDOT:PSS are well known as efficient hole-extracting layers in OPV cells, combining a high work function [11], good optical transparency, and ease of processing from solution $[12,13]$. But, it was observed that applying this extra PEDOT:PSS layer results in a decrease of the short-circuit current $\left(I_{\mathrm{sc}}\right)$ and fill factor (FF) owing to the bulk resistance of PEDOT:PSS [14]. In addition, it has also been suggested that the increase of series resistance will reduce the effective internal electric field in the active layer, which is essential for efficient charge collection to the electrodes from an organic photovoltaic model [15]. Therefore, the conductivity of PEDOT:PSS plays an important role in the polymer solar cells.

Devices with a better performance were achieved by inclusion of some good conductivity filler in the hole extraction layer. It has been reported that adding polyalcohols to PEDOT:PSS increases the conductivity and improves the efficiency of polymer PVs [16, 17]. Ko et al. [18] reported that improved power conversion efficiency has been observed by reducing the resistance of PEDOT:PSS after doping mannitol into the PEDOT:PSS.

Carbon nanotubes (CNTs) can also serve as a good filler for conducting polymer. It has been reported that incorporating CNTs into conventional conducting polymers improves the conductivity of CNTs/polymer composites by many orders of magnitude [19-23], which could be attributed to CNTs' large contact area, high dimensional aspect ratio, and exceptional electrical conductivity [24]. Our previous studies found that the conductivity of the PEDOT:PSS films increased drastically after inclusion of MWCNTs fillings [25].

In this article, the PEDOT:PSS doped with multi-walled carbon nanotubes (MWCNTs) film was fabricated and used 


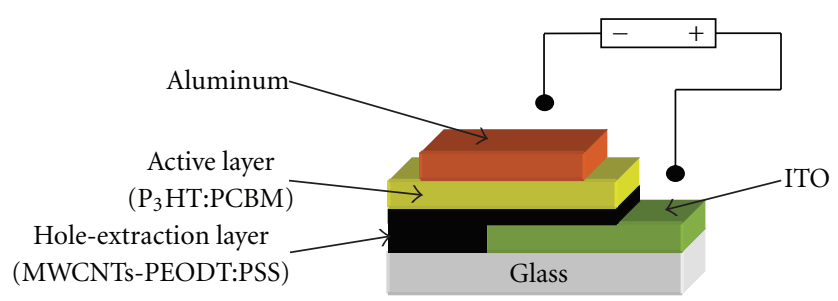

FIGURE 1: Schematic device structure for organic solar cells doped with MWCNTs.

as hole-extraction layer for OPV cells. The effect of MWCNTs concentration on the photovoltaic performance of the device based on $\mathrm{P}_{3} \mathrm{HT}$ :PCBM blend was investigated. Reasons for the improved performance of the devices were also discussed.

\section{Experimental}

Multi-walled carbon nanotubes (MWCNTs) (diameter: 10 $30 \mathrm{~nm}$, length: $5 \sim 15 \mu \mathrm{m}$, purity: >95\%) were purchased from Beijing Nachen Nanotech Co. Ltd., and the MWCNTs were further purified with strong acid. In a typical procedure, $30 \mathrm{mg}$ of MWCNTs was added into an acid solution of concentrated sulphuric acid $(15 \mathrm{~mL})$ and concentrated nitric acid $(5 \mathrm{~mL})$. The mixture was ultrasonicated for 20 minutes, stirred for 1 hour in reflux at $130^{\circ} \mathrm{C}$, vacuum filtered through a $0.2 \mu \mathrm{m}$ milli-pore polycarbonate membrane, washed with excess-distilled water until the $\mathrm{pH} 7.0$, and filtrated then dried under vacuum for $12 \mathrm{~h}$ at $60^{\circ} \mathrm{C}$.

PEDOT:PSS aqueous solution $(1.3 \mathrm{wt} \%$ dispersed in $\mathrm{H}_{2} \mathrm{O}$ ) from Aldrich (as supplied) was filtered with a $0.45 \mu \mathrm{m}$ polyvinyl difluoride (PVDF) syringe filter. Some amount of acid-treated MWCNTs were added into the PEDOT:PSS solution to form the nanocomposites. The composites were treated in ultrasonic bath for about 12 hours before using for spin coating.

All the devices in this work were fabricated using indiumtin-oxide- (ITO-) coated glass substrates $(<10 \Omega / \square)$. The ITO substrates were ultrasonically cleaned with a series of organic solvents (ethanol, methanol, and acetone), then rinsed in ultrasonic bath with deionized water and dried in a vacuum oven. Residual organic contaminations were subsequently removed by exposing to a UV-ozone lamp for 30 min. Nanocomposites of MWCNTs and PEDOT:PSS were spin coated on top of the ITO surface to form an (90$100 \mathrm{~nm}$ ) layer before drying the substrates at $120^{\circ} \mathrm{C}$ in an oven for more than $30 \mathrm{~min}$. The $\mathrm{P}_{3} \mathrm{HT}$ :PCBM was dissolved in dichlorobenzene at a weight ratio of $1: 0.8$ and stirred for more than $72 \mathrm{~h}$ in the glovebox before spin casting to form the blend layer. Finally an Al electrode of about $100 \mathrm{~nm}$ in thickness was deposited by thermal evaporation at a pressure of $2.4 \times 10^{-4} \mathrm{~Pa}$ through a shadow mask. No buffer layer between the organic layer and cathode is used. The basic structure of the OPV devices is shown in Figure 1.

The surface morphology of MWCNTs was carried out by field emission scanning electron microscopy (FESEM, JEOL,
JSM-6335 F). The optical property of the composite films was characterized with a TU-1901 Dual-beam UV-Visible spectrophotometer. Current density-voltage (I-V) characteristics of the PV cells were measured using a computercontrolled Keithley 2400 Source Meter in the dark and under a simulated light intensity of $100 \mathrm{~mW} / \mathrm{cm}^{2}$ (AM $1.5 \mathrm{G}$ ) calibrated by an optical power meter from a halogen lamp. The power conversion efficiency (PCE) was calculated from the I-V characteristics. The devices were tested in air without encapsulation.

\section{Results and Discussion}

Figure 2. compares the surface morphology of the MWCNTs before acid treatment (Figure 2(a)) and after acid treatment (Figure 2(b)). It can be see that particle-like impurity of MWCNTs is removed and the morphology, as in terms of the surface smoothness, is improved after the acid treatment. Moreover, the MWCNTs after acid treatment can be dispersed into aqueous PEDOT:PSS solution and no precipitation is observed in the solution after several weeks.

The transmittance of the nanocomposites is shown in Figure 3. The pristine PEDOT:PSS film gives a good optical transmittance (93.2\% average) on the wavelength range from $550 \mathrm{~nm}$ to $950 \mathrm{~nm}$, which corresponds to the power density of ambient sunlight on the Earth's surface [26]. However, the transmittance of PEDOT : PSS film decreases with increasing amount of MWCNTs. With the MWCNTs concentration increasing to $0.20 \mathrm{wt} \%$, the transmittance of composite film dropped by $7.5 \%$ ( $86.2 \%$ average $)$. This may result from the formation of the conductive network of MWCNTs and some absorptions of MWCNTs in the above wavelength range [27, 28].

Solar cells generally have a series resistance and shunt resistance associated with them. In practice, a high shunt resistance and a low series resistance are required simultaneously for an ideal photovoltaic device [29]. The shunt resistance usually reflects the degree of leakage current through the device, which relates to the overall quality of the films. Meanwhile, the series resistance is attributed to the ohmic loss in the whole device, which includes the resistance of the active layer, metal-organic contacts, the electrodes, and the conductivity of the hole-extraction layer [30].

The influence of the doping on the shunt resistance of the device can be observed in the I-V curves under lower bias in the dark. As appeared in Figure 4, at reverse negative bias and at the linear regime of forward bias, where the current is limited by shunt resistance due to the leakage current, the current gradually increases with the dopant concentration. The increasing current with doping concentration may be induced by random leakage current in higher conductivity M-PEDOT:PSS layer. Some phase separation and more defects caused by MWCNTs-doping in the PEDOT:PSS may have induced some leakage current through the device.

Figure 5 shows the current density-voltage curves of photovoltaic cells with different doping concentrations of MWCNTs in the PEDOT:PSS. The detailed parameters of devices are summarized in Table 1. 


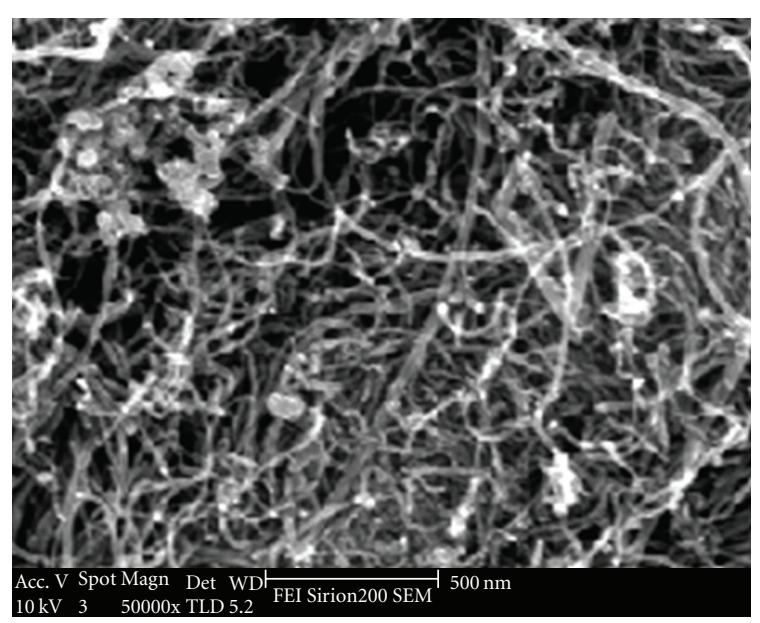

(a)

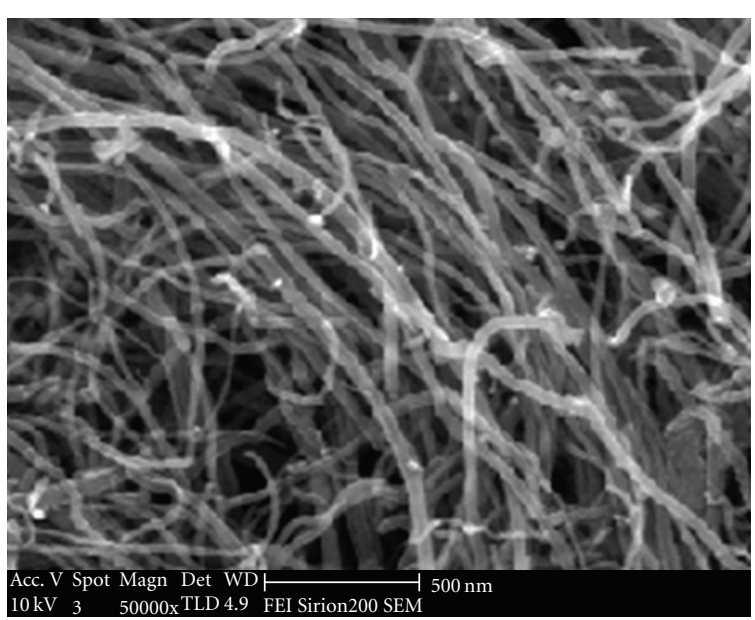

(b)

FiguRE 2: SEM of untreated and treated MWCNTs- (a) untreated MWCNTs; (b) treated MWCNTs

TABLE 1: PV parameters of OPVs for MWCNTs doping.

\begin{tabular}{|c|c|c|c|c|c|}
\hline Style & Structure & $V_{\mathrm{oc}}(\mathrm{V})$ & $I_{\mathrm{sc}}\left(\mathrm{mA} / \mathrm{cm}^{2}\right)$ & FF $(\%)$ & $\eta(\%)$ \\
\hline A & ITO/PEDOT:PSS/P ${ }_{3} \mathrm{HT}: \mathrm{PCBM} / \mathrm{Al}$ & 0.56 & 8.82 & 43.0 & $2.12 \%$ \\
\hline B & ITO/M (0.04 wt\%)-PEDOT:PSS/P 3 HT:PCBM/Al & 0.56 & 9.03 & 47.4 & $2.39 \%$ \\
\hline $\mathrm{C}$ & ITO/M (0.10 wt\%)-PEDOT:PSS/P ${ }_{3} \mathrm{HT}: \mathrm{PCBM} / \mathrm{Al}$ & 0.55 & 9.52 & 44.8 & $2.35 \%$ \\
\hline $\mathrm{D}$ & ITO/M (0.20 wt\%)-PEDOT:PSS/P ${ }_{3} \mathrm{HT}: \mathrm{PCBM} / \mathrm{Al}$ & 0.55 & 9.34 & 43.4 & $2.22 \%$ \\
\hline
\end{tabular}

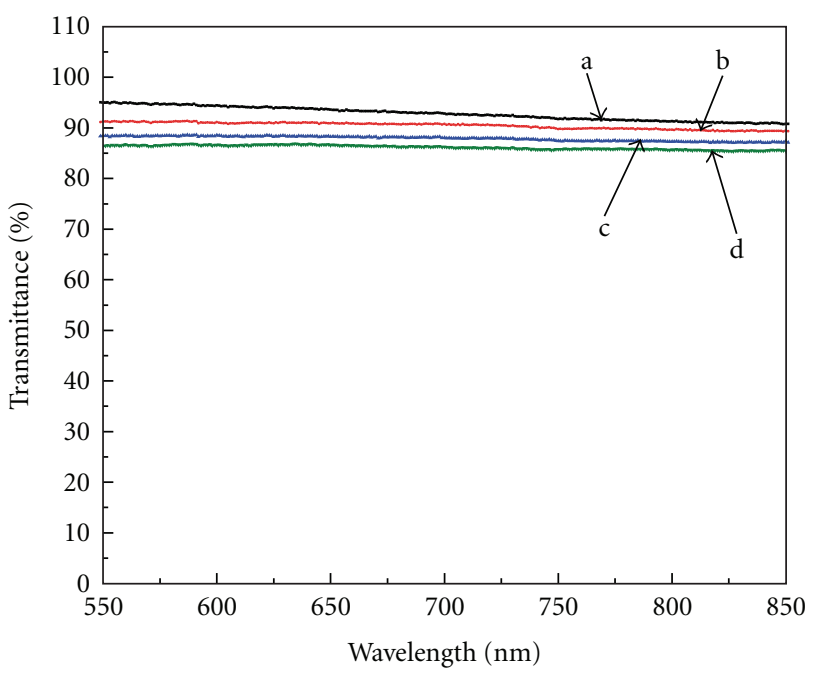
a: PEDOT:PSS
c: $\mathrm{M}(0.1 \mathrm{wt} \%)-$ PEDOT:PSS
b: M (0.04 wt\%)-PEDOT:PSS
d: $\mathrm{M}(0.2 \mathrm{wt} \%)$-PEDOT:PSS

FIGURE 3: The optical transmittance of films as a function of weight fraction of MWCNTs.

A small change in $V_{\text {oc }}$ with increase in MWCNTs amount was observed as shown in Table 1, where the values slightly vary around $0.56 \mathrm{~V}$. It was found that the open circuit voltage of the solar cell correlates directly with the work function of the electrodes or the buffer layers, that is, it is determined by the work function of PEDOT:PSS film [14, 17]. So the

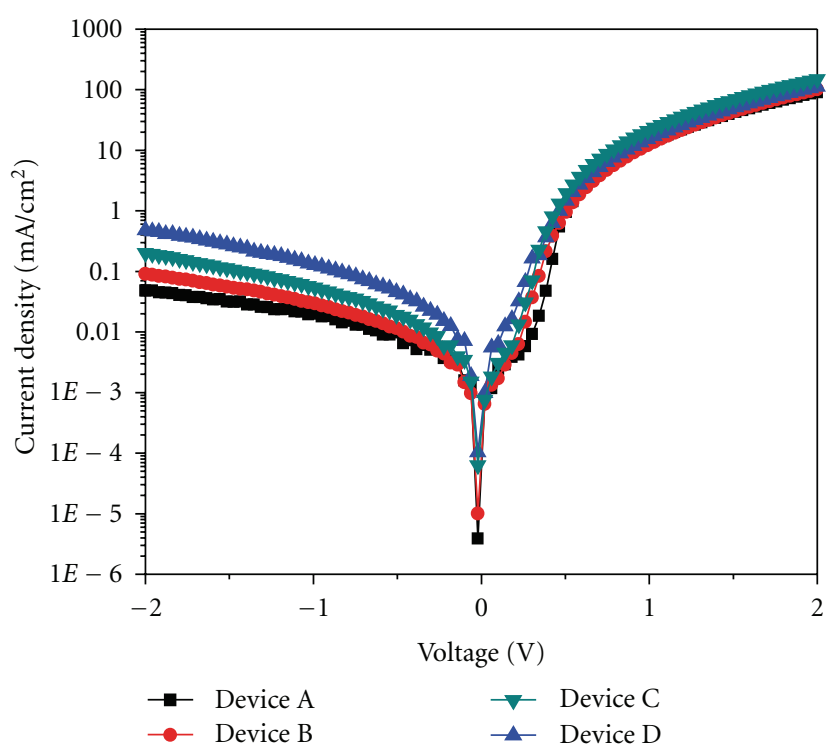

FIgURE 4: The dark I-V characteristics of devices with different concentrations of MWCNTs. Device A: pristine PEDOT:PSS film; Device B: M (0.04 wt \%)-PEDOT:PSS film; Device C: M (0.10 wt $\%)$ PEDOT:PSS film; Device D: M (0.20 wt\%)-PEDOT:PSS film.

addition of MWCNTs into PEDOT:PSS may not affect the work functions of PEDOT:PSS films in the solar cell.

Table 1 also shows the increase in $I_{\mathrm{sc}}$ from about $8.82 \mathrm{~mA} / \mathrm{cm}^{2}$ of the reference device A (0 $\mathrm{wt} \%$ doping) to 


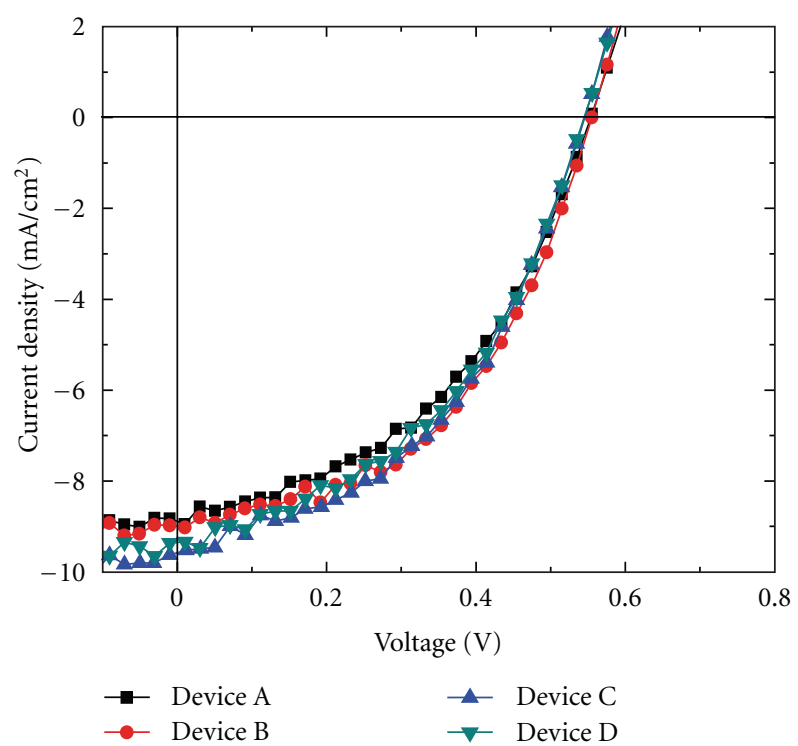

Figure 5: The I-V characteristics of devices with different concentrations of MWCNTs. Device A: pristine PEDOT:PSS film; Device B: M (0.04 wt \%)-PEDOT:PSS film; Device C: M (0.10 wt $\%)$ PEDOT:PSS film; Device D: M(0.20 wt\%)-PEDOT:PSS film.

$9.52 \mathrm{~mA} / \mathrm{cm}^{2}$ of the device $\mathrm{C}(0.10 \mathrm{wt} \%$ doping $)$, and after that the $I_{\mathrm{sc}}$ decreases to become $9.34 \mathrm{~mA} / \mathrm{cm}^{2}$ of the device $\mathrm{D}(0.20 \mathrm{wt} \%$ doping). Since these devices are fabricated with the same materials and the same procedure, and the only difference is the hole-extraction layer, the increased current is unlikely on account of other reasons, but due to the high conductivity of the composite hole-extraction layers, leading to a lower series resistance of the device. The generated hole carriers in the $\mathrm{P}_{3} \mathrm{HT}$ :PCBM active layer easily move into the anode through the MWCNTs-doped PEDOT:PSS layer. While the decrease in $I_{\mathrm{sc}}$ after adding more amount of MWCNTs may be due to the decrease of the transmittance of composite films in the wavelength around of $700 \mathrm{~nm}$ (as shown in Figure 3), which has effects on the photon absorption yield and the charge-carrier-transport yield of the PV cells [26]. The lowering of serial resistivity in holeextraction layers with increased MWCNT concentration is also responsible for increase in the fill factor from 0.43 to 0.474 . But as shown in Figure 4, extra amounts of the MWCNTs tend to decrease the OPV cells, shunt resistance, which can affect fill factor of OPV cells $[29,31]$. Then lower fill factor is obtained in device $\mathrm{C}$ and device $\mathrm{D}$.

The enhancement in both $I_{\mathrm{sc}}$ and FF by introducing MWCNTs into solar cell structure tends to cause improvement in the power conversion efficiency from $2.12 \%$ to $2.39 \%$, that is, by about $13 \%$.

\section{Conclusion}

In summary, We developed efficient OPV cells based on $\mathrm{P}_{3} \mathrm{HT}$ :PCBM blend by incorporating MWCNTs into holeextraction layer of PEDOT:PSS. Compared with the pristine OPV device without adding MWCNTs to the hole-extraction layer, the MWCNTs-doped OPV cells show an improved short-circuit current density, fill factor, and power conversion efficiency from 8.82 to $9.03 \mathrm{~mA} / \mathrm{cm}^{2}, 0.43$ to 0.474 , and $2.12 \%$ to $2.39 \%$ (i.e., by about $13 \%$ ), respectively. The high electrical conductivity properties of the composite films might contribute to facility the hole-extraction and holetransport ability of PEDOT:PSS, which leads to the reduction of series resistance of the devices.

\section{Acknowledgment}

Financial support from the program for New Century Excellent Talents in University (NCET, Grant no. NCET-040648) is gratefully acknowledged.

\section{References}

[1] T. D. Nielsen, C. Cruickshank, S. Foged, J. Thorsen, and F. C. Krebs, "Business, market and intellectual property analysis of polymer solar cells," Solar Energy Materials and Solar Cells, vol. 94, no. 10, pp. 1553-1571, 2010.

[2] B. Kippelen and J. L. Brédas, "Organic photovoltaics," Energy and Environmental Science, vol. 2, no. 3, pp. 251-261, 2009.

[3] M. Helgesen, R. Søndergaard, and F. C. Krebs, "Advanced materials and processes for polymer solar cell devices," Journal of Materials Chemistry, vol. 20, no. 1, pp. 36-60, 2010.

[4] F. C. Krebs, "Fabrication and processing of polymer solar cells: a review of printing and coating techniques," Solar Energy Materials and Solar Cells, vol. 93, no. 4, pp. 394-412, 2009.

[5] D. Y. Kim, F. So, and Y. Gao, "Aluminum phthalocyanine chloride/C organic photovoltaic cells with high open-circuit voltages," Solar Energy Materials and Solar Cells, vol. 93, no. 9, pp. 1688-1691, 2009.

[6] J. S. Kim, J. H. Park, J. H. Lee, J. Jo, D. Y. Kim, and K. Cho, "Control of the electrode work function and active layer morphology via surface modification of indium tin oxide for high efficiency organic photovoltaics," Applied Physics Letters, vol. 91, no. 11, pp. 2111-2113, 2007.

[7] C. C. Wu, C. I. Wu, J. C. Sturm, and A. Kahn, "Surface modification of indium tin oxide by plasma treatment: an effective method to improve the efficiency, brightness, and reliability of organic light emitting devices," Applied Physics Letters, vol. 70, no. 11, pp. 1348-1350, 1997.

[8] F. Liu, S. Shao, X. Guo, Y. Zhao, and Z. Xie, "Efficient polymer photovoltaic cells using solution-processed $\mathrm{MoO}_{3}$ as anode buffer layer," Solar Energy Materials and Solar Cells, vol. 94, no. 5, pp. 842-845, 2010.

[9] S. W. Tong, C. F. Zhang, C. Y. Jiang et al., "Improvement in the hole collection of polymer solar cells by utilizing gold nanoparticle buffer layer," Chemical Physics Letters, vol. 453, no. 1-3, pp. 73-76, 2008.

[10] R. A. Hatton, N. P. Blanchard, LI. W. Tan, G. Latini, F. Cacialli, and S. R. P. Silva, "Oxidised carbon nanotubes as solution processable, high work function hole-extraction layers for organic solar cells," Organic Electronics, vol. 10, no. 3, pp. 388395, 2009.

[11] T. M. Brown, J. S. Kim, R. H. Friend, F. Cacialli, R. Daik, and W. J. Feast, "Built-in field electroabsorption spectroscopy of polymer light-emitting diodes incorporating a doped poly(3,4-ethylene dioxythiophene) hole injection layer," Applied Physics Letters, vol. 75, no. 12, pp. 1679-1681, 1999. 
[12] G. Heywang and F. Jonas, "Poly(alkylenedioxythiophene)snew, very stable conducting polymers," Advanced Materials, vol. 4, no. 2, pp. 116-118, 1992.

[13] L. Groenendaal, F. Jonas, D. Freitag, H. Pielartzik, and J. R. Reynolds, "Poly(3,4-ethylenedioxythiophene) and its derivatives: past, present, and future," Advanced Materials, vol. 12, no. 7, pp. 481-494, 2000.

[14] T. Aernouts, W. Geens, J. Poortmans, P. Heremans, S. Borghs, and R. Mertens, "Extraction of bulk and contact components of the series resistance in organic bulk donor-acceptorheterojunctions," Thin Solid Films, vol. 403-404, pp. 297-301, 2002.

[15] B. Mazhari, "An improved solar cell circuit model for organic solar cells," Solar Energy Materials and Solar Cells, vol. 90, no. 7-8, pp. 1021-1033, 2006.

[16] F. Zhang, M. Johansson, M. R. Andersson, J. C. Hummelen, and O. Inganäs, "Polymer photovoltaic cells with conducting polymer anodes," Advanced Materials, vol. 14, no. 9, pp. 662$665,2002$.

[17] F. L. Zhang, A. Gadisa, O. Inganäs, M. Svensson, and M. R. Andersson, "Influence of buffer layers on the performance of polymer solar cells," Applied Physics Letters, vol. 84, no. 19, pp. 3906-3908, 2004.

[18] C. J. Ko, YI. K. Lin, F. C. Chen, and C. W. Chu, "Modified buffer layers for polymer photovoltaic devices," Applied Physics Letters, vol. 90, no. 6, Article ID 063509, 2007.

[19] H. Peng and X. Sun, "Highly aligned carbon nanotube/polymer composites with much improved electrical conductivities," Chemical Physics Letters, vol. 471, no. 1-3, pp. 103-105, 2009.

[20] Z. Yang, H. Pu, J. Yuan, D. Wan, and Y. Liu, "PhthalocyaninesMWCNT hybrid materials: fabrication, aggregation and photoconductivity properties improvement," Chemical Physics Letters, vol. 465, no. 1-3, pp. 73-77, 2008.

[21] M. C. Wu, Y. Y. Lin, S. Chen et al., "Enhancing light absorption and carrier transport of P3HT by doping multi-wall carbon nanotubes," Chemical Physics Letters, vol. 468, no. 1-3, pp. 6468, 2009.

[22] K. R. Reddy, B. C. Sin, K. S. Ryu, J. C. Kim, H. Chung, and Y. Lee, "Conducting polymer functionalized multi-walled carbon nanotubes with noble metal nanoparticles: synthesis, morphological characteristics and electrical properties," Synthetic Metals, vol. 159, no. 7-8, pp. 595-603, 2009.

[23] T. M. Wu, H. L. Chang, and Y. W. Lin, "Synthesis and characterization of conductive polypyrrole/multi-walled carbon nanotubes composites with improved solubility and conductivity," Composites Science and Technology, vol. 69, no. 5, pp. 639-644, 2009.

[24] R. H. Baughman, A. A. Zakhidov, and W. A. De Heer, "Carbon nanotubes-the route toward applications," Science, vol. 297, no. 5582, pp. 787-792, 2002.

[25] C. Gao, J. Li, J. Liu, J. Zhang, and H. Sun, "Influence of MWCNTs doping on the structure and properties of PEDOT:PSS films," International Journal of Photoenergy, vol. 2009, Article ID 650509, 5 pages, 2009.

[26] B. R. Saunders and M. L. Turner, "Nanoparticle-polymer photovoltaic cells," Advances in Colloid and Interface Science, vol. 138, no. 1, pp. 1-23, 2008.

[27] S. Ghosh and O. Inganäs, "Self-assembly of a conducting polymer nanostructure by physical crosslinking: applications to conducting blends and modified electrodes," Synthetic Metals, vol. 101, no. 1-3, pp. 413-416, 1999.

[28] J. K. W. Sandler, J. E. Kirk, I. A. Kinloch, M. S. P. Shaffer, and A. H. Windle, "Ultra-low electrical percolation threshold in carbon-nanotube-epoxy composites," Polymer, vol. 44, no. 19, pp. 5893-5899, 2003.

[29] H. Z. Yu and J. B. Peng, "Influence of the solvent and device structure on the performance of the MEH-PPV:PCBM solar cell," Acta Physico-Chimica Sinica, vol. 23, no. 10, pp. 16371641, 2007 (Chinese).

[30] J. Xue, S. Uchida, B. P. Rand, and S. R. Forrest, " $4.2 \%$ efficient organic photovoltaic cells with low series resistances," Applied Physics Letters, vol. 84, no. 16, pp. 3013-3015, 2004.

[31] D. Gupta, S. Mukhopadhyay, and K. S. Narayan, "Fill factor in organic solar cells," Solar Energy Materials and Solar Cells, vol. 94, no. 8, pp. 1309-1313, 2010. 


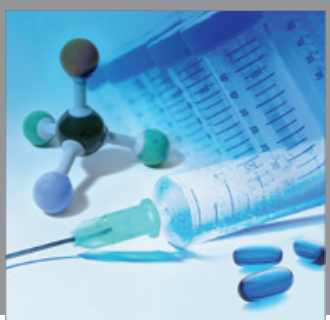

International Journal of

Medicinal Chemistry

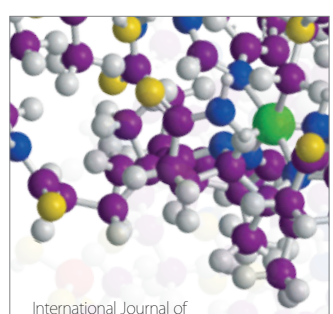

Carbohydrate Chemistry

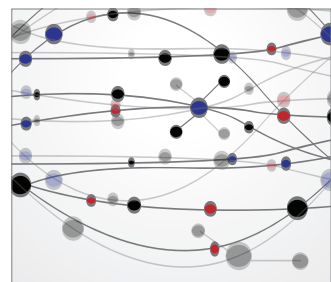

The Scientific World Journal
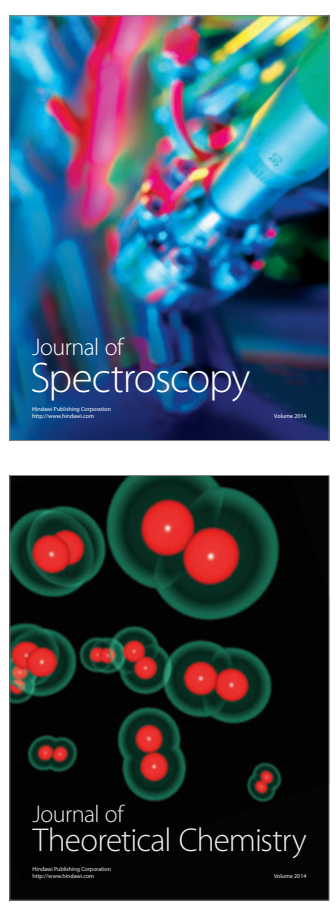
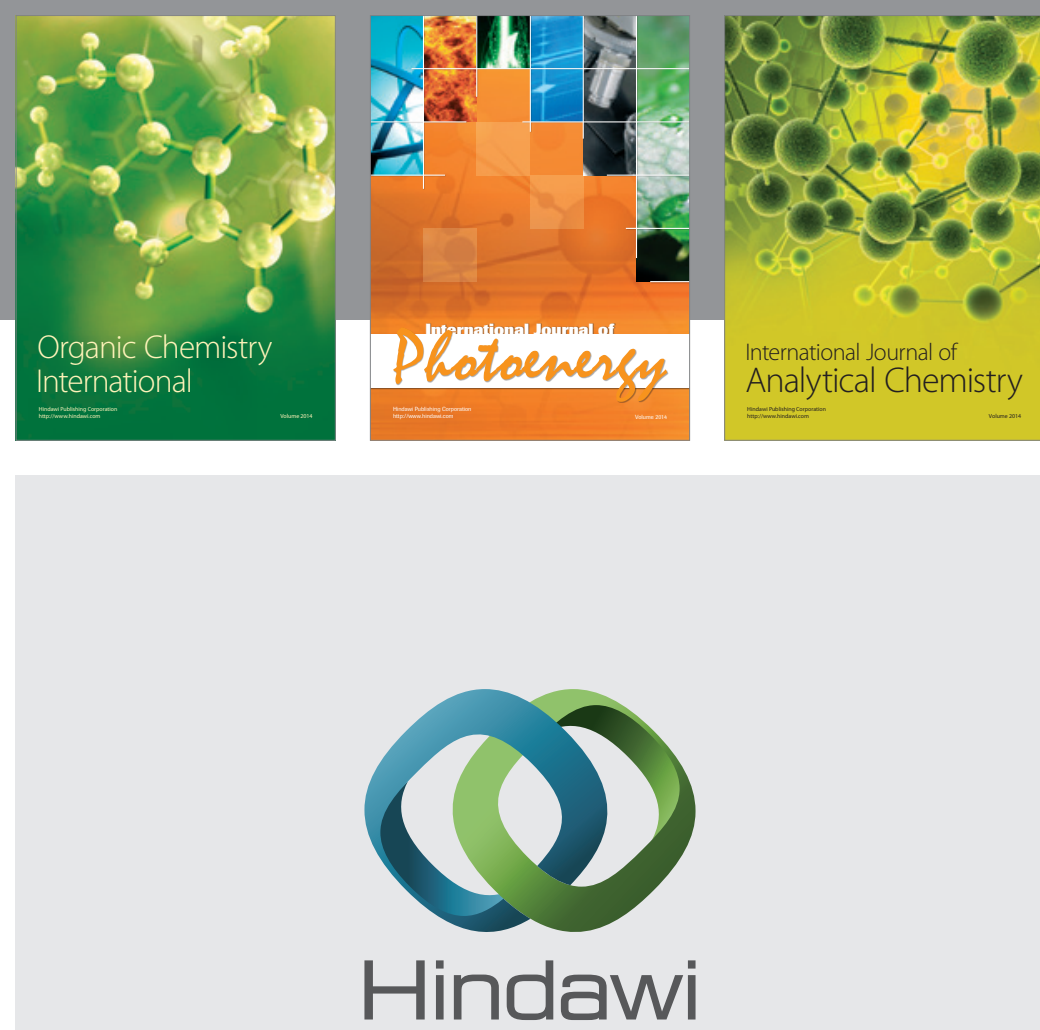

Submit your manuscripts at

http://www.hindawi.com
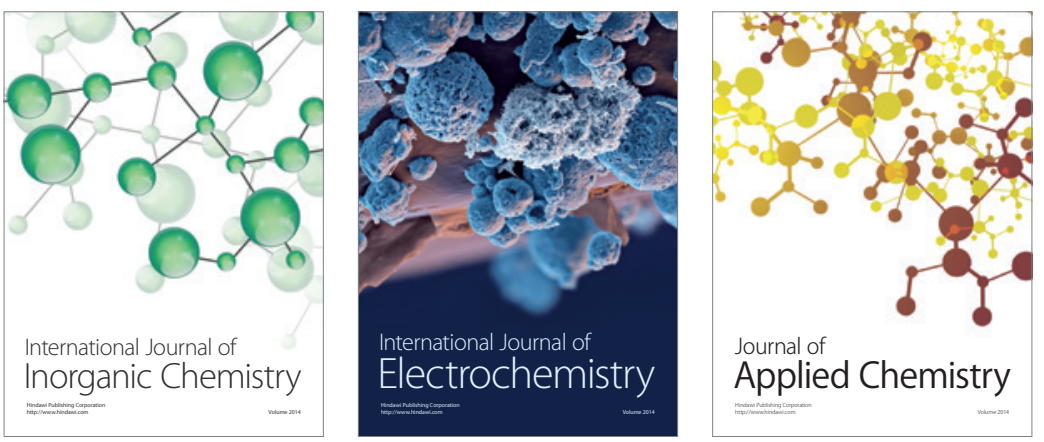

Journal of

Applied Chemistry
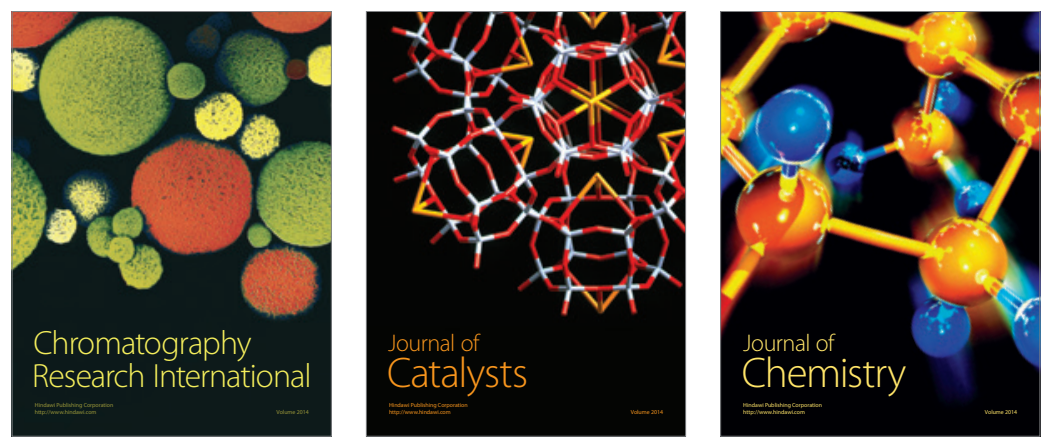
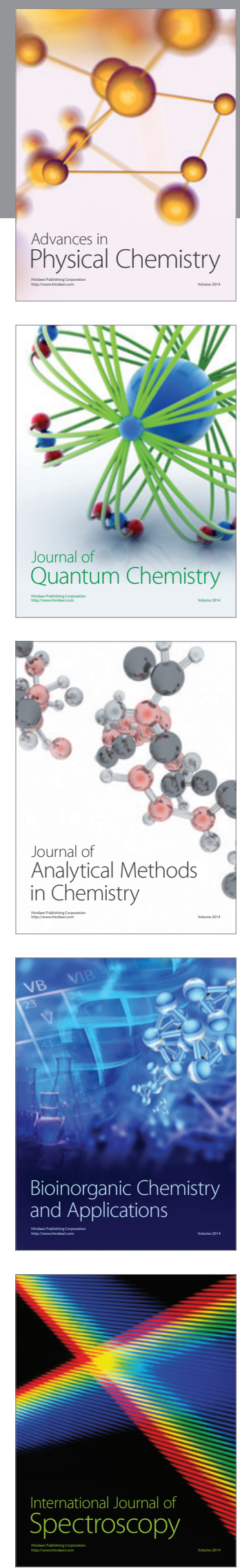